\title{
A presença dos primeiros japoneses no Brasil
}

\author{
Tomoko Kimura Gaudioso
}

\section{Introdução}

No dia 18 de junho de 1908, ano 41 da era Meiji', o navio Kasato-maru aportou no porto de Santos trazendo os primeiros 781 japoneses contratados para trabaharem nas fazendas de café e mais 12 imigrantes sem vínculo empregatício. HANDA (1981) descreve minuciosamente a reação de primeiros japoneses imigrantes que pisaram no solo brasileito tendo em vista a dificuldade em se adaptar à cultura e à língua totalmente diferente com as do Japão². Foi o início da imigração japonesa. Desde então, salvo o período de restrição de entrada de estrangeiros no início do século XX e durante a II Guerra Mundial, a imigtação dos japoneses ao Brasil tã̃o conheceu freios.

Os descendentes japoneses, identificados como nikkeis ${ }^{3}$, ocupam atualmente uma significativa fatia da população brasileira contribuindo para o desenvolvimento do país. Para se ter uma noção do crescimento populacional dos nikkeeis, comparemos seu número desde que chegaram ao Brasil. Em 1908, 791 japoneses desembarcaram em Santos. Em 1978, ao comemorarem $070^{\circ}$ ano desde a chegada, o seu númeto havia aumentado para $700 \mathrm{mil}$ pessoas. Em 1998, ao comemorarem o $90^{\circ}$ ano da imigração, o número de nikketis havia ultrapassado a casa de um milhão e meio de pessoas, sendo que mais 200 mil nikekeis

${ }^{\prime}$ No Japão, utiijza-se paralelamente ao calendário gregoriano, o calendátio por exa da dỉnastia de cada imperador. O calendário refere-se a exa do Imperador Meiji, que perdurou de 1868 até 1912 . O calendátio gregoriano foi adotado no Japäo somente en 1900. Sobre calendário, é interessante consultar NAGATA,

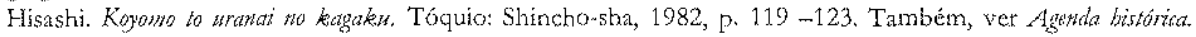
Tóquio: Yoshikawa Kobunkakx, 2001 p. 8 e ss.

${ }^{2}$ Sobte o assunto, ver HANDA, Tomoo. Imin no seikaturu no rekishis.(História da imigração japonesà). São Paulo: Centro de Estudos Nippo Brasileiro, 1981.p.10 e ss. Tambén ver: REIS, Maria Edileuza Fontenele, Brasileiros no Japão: o to bumano das relatões bilaterats. NINOMIYA, Masato, org. e trad. 2.ed. São Paulo: Kaleidus-Primus, 2002, p. 10.

${ }^{3}$ As pessoas de origem japoresa säo designadas de Nikki, i.e., os indivíduos que tern na sua ascendência alguém de nacionalidade japonesa. Para ser considetado nikket, pottanto, deve ter na sua linkagem o sangue japonês. Por analogia, também se utiliza essa palava para definir empresas japonesas que atuam no exterior. 
brasileiros trabalham no Japão como dekasseguis fornecendo a mão-de-obra necessátia para o crescimento econômico japonês e, por outro lado, trazendo divisas significativas para o Brasil.

Os japoneses e seus descendentes no Brasil comemoram o dia 18 de junho como o Dia da Imigração Japonesa. Grandes festividades são realizadas pelos nikkeis em todo o Brasil, de norte a sul. O contato dos japoneses com o solo brasileito, porérn, iniciou-se muito antes da referida data. Apesar de ser praticamente desconhecido mesmo pelos historiadores, o fato é que, em novembro de 1803, quatro náufragos japoneses salvos pelos russos estiveramn na tha de Santa Catarina a bordo do navio Nadiezheda ${ }^{5}$. Essa expedição, além dos quatro japoneses, era composta pelo Capitão Ivan Fyodorovich Krusenshtern, emissário do império russo N. P. Rezanov e mais 79 tripulantes entre médicos, astrônomos, naturalistas, pintor, imediatos e outros. Os náufragos estavam iniciando naquele momento o laço da relação internacional com o Japão, mesmo sem se dar conta da importância do fato.

O Brasil, que o Japão conhecia apenas através das informações obtidas nas bibliografias, passou a ser concreto. Saiu da ficção e tornou-se efetivo, trazendo esperança para a internacionalização do país antes praticamente isolado do mundo.

Esses quatro náufragos certamente contribuíram profundamente para a futura concretização do tratado de amizade firmado entre Japão e Brasil. É através deles que os japoneses, vivendo na clausura pelo fechamento dos portos decretado pelo shogunato de Tokugawa, passam a conhecer a imensidão do mundo de forma mais concreta ${ }^{6}$. Os náufragos, como os primeiros japoneses que fizeram uma viagem completa do hemisfério norte ao bemisfério sul, forneceram uma importante descrição sobre tudo que viram em suas viagens, inclusive no solo brasileiro, identificando semelhanças nos produtos aqui encontrados, o que confirma a afinidade dos japoneses com o Brasil.

Kankai Ibun (Informações exóticas ouvidas na viagem realizada ao redor do mundo), organizado por OTSUKI Gentaku (1757-1827) e SHIMURA Hiroyuki (1769-1845) em 1807, é o documento mais antigo que registra o conrato dos japoneses com o solo brasileiro.

Para comemorar os 200 anos deste contato, foi realizada a tradução do volume 12 do documento organizado por esses autores, que trata exatamente das anotações de relato das experiências dos náufragos que viajaram pela rota atlântica até chegarema à Iha de Santa Catarina e sua partida numo ao Oceano Pacífico através do Estreito de Magalhães. O texto é acompanhado de uma análise histórica da época para melhor situar o leitor quanto ao seu conteúdo.

\footnotetext{
${ }^{4}$ A palavra dekassegui significa trabalhador que se desloca de seu domicilio para obter emprego tempotário.

"Nadiezheda: a palavra nadiezbeda significa "esperança" em lingua russa. Neste lugar gostaria de agradecer à professora Tanira Castro do Setor Russo, Instituto de Letras da UFRGS pela ajuda referente à língua russa.

- O Japão viveu isolacionismo no periodo de 1639 a 1858 quando o governo de Bakufu governo de militares) limitou o contato com ocidente somente com os holandeses. O governo da época temia a colonização do país pelos portugueses que pregavan o cristianismo.
} 


\section{O Japão isolado}

O Japão foi divulgado pela primeira vez na Europa por Marco Polo, no final do século XIII. Nessá época, o Japão havia sofrido duas tentativas de invasôes mongóis, a primeito em 1274 e a segunda em 1281, que não se concretizaram?7. Em 1542 ou em 1543, náufragos lusitanos chegaram na Ilha de Tanegashima. Foi o primeiro contato dos europeus com o Japão ${ }^{8}$. Desde então até 1639, os portugueses mantiveram um intenso comércio com o Japão. Ao mesmo tempo, os jesuítas divulgaram o cristianismo naquela ilha".

A partir da segunda década do século XVII, sob a influência dos holandeses que desejavam afastar os portugueses do comércio com o Japão, a política do shogunato em relação aos países estrangeiros se alterou, tendendo ao fechamento do país. Criou-se em 1636 a ilha de Deshima, um ilha artificial em Nagasaki, onde aos navios estrangeiros eta permitido aportar.

En 1636, sob o governo de shogunato ${ }^{10}$, o shogun Iemitsu Tokugawa iniciou o processo de isolamento do Japão do resto do mundo, extinguindo as atividades dos navios oficiais denominados shuin-sen ${ }^{7 t}$ e proibindo seus súditos de saítem do país. Em 1639, em decorrência da Rebelião de Shimabara (1637-1638), que envolveu cristãos católicos, o governo determinou a proibição definitiva da estada dos portugueses completando, assim, o processo de isolamento do Japão ${ }^{12}$. Aos holandeses que não seguiam o catolicismo foi concedida a licença para aportarem exclusivamente na ilha artificial de Deshima. O único contato do Japão com o ocidente passou a ser através dos holandeses que vinham a essa ilha com interesses comerciais. No Japão, então isolado, desenvolveu-se o estudo sobre o ocidente chamado rangakut ${ }^{13}$. As informações sobre os países estrangeiros passaram a set obtidas somente através dos holandeses, a veracidade de seus conteúdos baseava-se exclusivamente na confiança nos livros japoneses.

${ }^{7}$ KEENE, Donald et alii. Mongorw no stuturai. In: Visual Human Life: the nippon. Tokyo: Kodansha, 1986. P. $578-579$.

${ }^{8}$ Como escreve Reishauer, "A sixteenth century folding screen, depicting Portuguese in the strects of Japan. Reaching Japan in 1542 or 1543, the Portuguese were the Frst Europeans the Japanese had ever seen, and the Japanese were fascinated by theirs trange costumes and curious physiognomy." In: REISHAUER, Edwin O. The japanese, Tokyo: Charles B. Tuttle Co., 1987, p. 69.

"Sobre o assunto, cf.: IKUNIYOSHI, Cclina. Imagens do Japão. São Paulo: Estação liberdade, 1998, p. $32-33$.

10 Sbogunato: Sistema de governo inaugurado em 1192, quando Minamoto Yoritomo, em 1185, foi nomeado pelo imperador Sei-1-Taishogun (generalissimo no comando das forças de repressão aos bárbaros). Continuou até a Restauraçāo Meiji (1868). Abrevidado para shogum, passou a designar o chefe de governo militar hereditário. Cf.: IKUNIYOSHI, op. cit., p. 58-59.

"Os navios mercantes recebian permissöes oficiais com selo vermelho (shuin)para exercer atividades de comércio com paises estrangeiros, principalmente com a China. O navio que possuía esse selo era chamado de stuin sen ( navio de selo vermelho).

12 Esse isolamento durou até 1868 quando o sistema de governo estabelecido pelo shogunato denominado bakuban foi extinguido pela retomada do poder pelo imperador Meiji. Sobre ó assunto, ver KUNIYOSHI, op. cit., p.39-41. Ver também, HLALI, John Winey. El imperio japonés.Madrid: Siglo XXI de Espãna Editores, 1973.

13 Rangatex: era assim chamado o estudo sobre os conhecinentos vindos do ocidente trazidos pelos holandeses. Sobre o assunto, ver: KUWWABARA, Takeo. Japan ando western aitilization. Tokyo: University of Tokyo, 1986. 
Entretanto, enquanto o Japão isolava-se do resto do mundo por quase duzentos anos, o ocidente experimentava grandes mudanças políticas, sociais e econômicas. A Europa estava submergida na política de expansão sendo que na Ásia, a Índia passava às mãos dos ingleses (1858-1947) e a Guerta de Ópio (1840-1842) assolava a China. A Rússia, localizada ao extremo leste do continente eutopeu e ao norte da $A$ sia, ao mesmo tempo que expandia o seu território para o oeste europeu procurava um porto que não congelasse durante o inverno para ter acesso ao Pacifico. A localização geográfica do Japão serviria a esse intuito.

O contato oficialmente reconhecido entre Rússia e Japão iniciou-se em maio do ano 4 da era Kansei (1792) quando o Governador de Sendai ${ }^{14}$, Sadanobu Matsudaira apreendeu e confiscou os livros "Sangoku Tsuuranzu Setsu" e "Kaikakm Heidan" escritos por Shihei Hayashi. Os livros alertavam sobre o perigo vindo do além mar e a necessidade do fortalecimento da força de defesa marítima. Ao autor foi ordenada a prisão domiciliar.

Cinco meses mais tarde, em setembro de 1792 , o emissátio russo A. K. Laksman (1766-1803?) chegou à localidade ao norte do Japão chamada Nemuro solicitando o tratado de comércio, acompanhado do tradutor japonês-russo Kotato Hyotatoich, um náufrago japonês radicado na Rússia. Laksman obteve na ocasião a licença para aportar em Nagasakikit5 sem, no entanto, firmar tal tratado.

Entretanto, o Japão não ficou estático às mudanças do tempo. Após receber vátias informações vindas dos náufragos que tiveram contatos com os russos e sentindo a necessidade de verificar melhor a extensão de seu território, no ano 10 da era Kansei (1798), foi formada uma expedição de mais de cem pessoas, liderados por Tokunai Mokami e Jyuzo

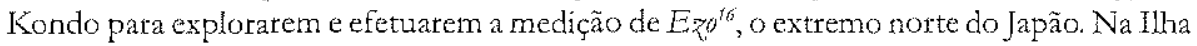
de Etorofu ${ }^{17}$, os japoneses derrubaram o marco deixado pelos russos e levantaram um outro no lugar dele escrito "Etorofu do Grande Japão". No ano um da era Kyowa (1801), uma outra expedição japonesa desembarcou na Ilha de Urupp ${ }^{18}$ que era colônia da Rússia e colocou o marco dizendo que aquela ilha pertencia ao Japão. No ano dois da era Kyowa (1802), o governo japonês instalou a sede de controle da região de Eq. $0^{19}$. A hostilidade japonesa em relação à Rússia havia aumentado desde que Laksman chegou no Japão dez anos arrás. A tentariva da Rússia em devolver os quatro náufragos japoneses e firmar um tratado de amizade como Japão, em 1803, não obteve sucesso.

it Sendai: um dos distritos do Japão a extremo do Honshu, a ilha principal.

${ }^{15}$ Cf.: SUGMOTO, Tsutomu et alii. Kankai Yhun: bonbun to kenkyu. Tokyo: Hasaka shobo, 1986.

is Ezo: a pasavra ezo ou emishi indica tanto povo ainu que habita região ao extremo norte do Japão como o próprio lugar. Também é chamado de Yezo pelos ocidentais.

1? Eorofu ou ltutup: ilha existente ao norte do Japão alén da Itha de Hokkicio, Japão

"Ljupp: ilha existente ao norte da Etorofu, já próximo a pexínsula de Kamchatka, Rússia.

"Segundo Reishauer, entre a Rússia e Japão sempre houve hostilidades. Diz ele que essa hostilidade iniciou-se ainda na época da Rússia czarista do século XVII, pela disputa das illas de Hokkaido, Sahkirin e as thas Kuriles. Essa disputa que culminou na guerra russo-japonesá (1904-1905) só teve fim após a II Guerra Mundial. Sobre o assunto, ver: REISHAUER, Edwin O. Op. cit., p. 415-416. Também, ver: IKEDA, Akira. Kankai Ybun: Kai Dai. Tokyo: Omatsudo Shuppan, 1989, p. 305 e ss. 
Demoraria ainda pot mais de meio século para o Japão passar a abrir os seus portos ao ocidente, num processo gradual e de difícil adaptação $o^{20}$.

\section{Relações Internacionais do Brasil no século XVIII e no século XIX}

Quanto ao Brasil, desde a sua época colonial quando pertencia ao Reino de Portugal, sempre esteve em contato com outros povos através das relações diplomáticas. Quanto à menção ao porto de Santa Catarina no documento que relata a vinda dos japoneses, sua veracidade é ainda mais confirmada pelo fato desse porto ser um dos portos mais importantes da época. Só para citar um exemplo, o livro sobre Relações Diplomáticas do Brasil de 1808 a 1912, organizado por Raul Adalberto de Campos cita que:

'Na convenfão secreta relativa à transnigraça de familia real assinada em Londres a 22 de outubro de 1807, pactuava-se que, no caso de se fecharem os portos de Portugal a bandeira inglesa, seria estabelecido um porto na ilha de Santa Catarina ou em outro lusar da costa do Brasil, por onde as mercadorias portuguesas e britanicas poderiam ser iniportadas em navio. ingleses, pagando os mesmos diweitos que pagavam atwalmente en portugal e durando este acordo até o nowo ajuste.

O artigo acima referido escrito pelo médico José Corteia Picanço, que convenceu D. João VI a fundar a primeira escola médico-cirúrgica no Brasil, mostra claramente que a liha de Santa Catarina, no início do século XVIII, era um dos portos mais importantes no Brasil para o escoamento de mercadorias, tanto para importação como para exportação. Assim, o depoimento dos náufragos aponta, sem dúvida, a llha de Santa Catarina ${ }^{22}$, onde os navios russos carregavam mercadorias brasileiras para levar ao seu país.

A Rússia mantivera naquela época, ainda durante o período do Brasil colonial, relação diplomática com o Reino de Pottugal, através do Tratado de amizade, navegação e comércio assinado em 27 de dezembro de 1798, o qual mais tarde foi prorrogado em Declaração de 29 de março de 1815 , assinada em Viena ${ }^{23}$. Certamente, se Portugal não tivesse firmado esse tratado com o império russo, os japoneses não teriam chegado ao Brasil naquela ocasião e o Japão não teria obtido uma visão global da imensidão do mundo.

2) Depois de firmar tratados de amizade com alguns paises como Ingaterra e Estados Unidos, o Japão passou por um período de crise conômica com inflação no mercado interno devido ao excesso de exportações e falta de mercadorias para o consumo. $O$ governo japonês, diante das revoltas poptiares e de vátios incidentes diplomáticos, cogita $\mathrm{cm}$ fechar novamente os portos ao ocidente attavés da elaboraçăo da lei de expulsão de escrangeiros, Jout, em

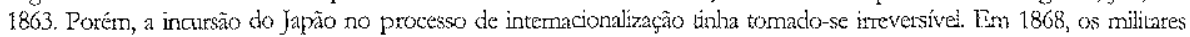
devolvern o poder nas mãos do lmperador Mciji, o gual decide abrir os portos defuitivamente aos páses estrangeiros.

${ }^{21}$ Fonte: RIBEIRO, João. Histótia do Brasil. Rio de janeiro: Livraria São José. $15^{2}$ ed. 1954, p.2\%.

22 A capitania de Santa Catarina que injeialmente fazia parte da capilania de Santo Amaro, doada a Pêro Lopes de Souza, em 1711 incorporada à coroa portuguesa. Eut 1723, por ordem real, injcia-se a colonizaçäo pelos açorianos e colonos vindos da Tha de Madeira. Em 1739, a sede do govemo de Santa Catarixa muda-se para povoado o de

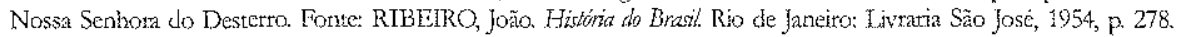

${ }^{23}$ Ver: CAMPOS, Raul Adalberto de. Relapoes diplowalicaf do Bratil de 1808 a 1912 Rio de Janeiro, Tyip. Jornal do commetcio, $1913, \mathrm{p}, 98$. 


\section{A trajetória dos náufragos}

O documento mais antigo que registra o contato dos japoneses com o solo brasileiro é Kankai Ibun (Informações exóticas ouvidas na viagem ao redor do mundo), organizado por OTSUKKI Gentaku (1757-1827) e SHIMURA Hiroyuki (1769-1845) em 1807.

OTSUKI, no volume 15 do depoimento assim comenta sobre a viagem dos marinheiros:

"(...) Enumerando os locais e pessoas de costumes e linguas diferentes que os náufragos encontraram no caminho de volta da Rüssia ao Japãa, comefando-se pela primeira ilba em que os náufragos chegaram, podemos citá-los como a seguir:

1. Aleutas nome atribuido aos nativos das Ilhas Onderetsuke. Kotaro comenta que eles se chamain Aleotska;

2. Okhotk - nome do porto do Continente;

3. Kamtchad - o que é natural da Kamtchaka;

4. Yakote - pessoas e locais referentes a Yakotsk;

5. Bratsk - nome referente aos nativos próximos a Yrktsk;

6. Tungus - refere-se a pessoas da região de Tungus;

7. Taruta-tártaros

8. Ketaitske " montanhas da China

9. Chivachwa - nome do local a meio camintio entre a nova Capitale Yretsk;

10. Kameika - nome referente aos babitantes ao norte do Moscou;

11. Arap - negro (provavelmente americano);

12. Karla- año;

13. Swetsuke-Suécia;

14. Angeskoi - Inglaterra;

15. Fransosuke- Frances;

16. Dantske - Dinamara;

17. Ishipan - Espanba;

18. Portokali - Portugal;

19. Kanaritske-Ilhas Canárias (dizem que foram colonizadas pelos espanboiss);

20. Ecatherina - América do Sul, Brasil;

21. Ilha Marquesa - Ilha isolada na América;

22. Sanbeittee - idem ao anterior (essas duas ilbas devem pertencer à América do Norte)."

Otsuki comenta sobre isso que com esses vinte e dois nomes de locais e de povos citados pôde conhecer os aspectos dos povos da América do Norte, Ásia, Europa, África e América do Sul. Deve-se comentar ainda, que a primeira ilha, onde os náufragos chegaram depois de se terem perdido no mar, pertencia, na opinião de Otsuki, à América do Norte (região do Alasca). Havia se iniciado uma visualização real da proporção e variação geográfica do planeta Terra, por parte dos japoneses.

O documento relata a partida do navio Wakamiya-maru carregado de sacas de arroz do porto de Ishinomaki, Sendai, ao norte do Japão com destino a Edo, atual Tóquio, no dia 
27 de novembro de 1793, ano 5 da era Kansei. Carregavam 1300 sacas de arroz e 400 toras de madeira. Seus tripulantes etam no total de dezesseis homens, entre capitão, marinheiros e cozinheiro. Eram eles Heibei (31 anos), Tsudayu (49 anos), Sadayu (51 anos), Gihei (32 anos), Kichijirou (67anos), Sahei (31 anos), Taminosuke (30 anos), Ginsaburou (29 anos), Shigejirou (29 anos), Ichigorou (29 anos), Yasaburou (25 anos), Zenroku (24 anos), Tajurou (23 anos), Tatsuzou (22 anos), Yoshizou (dade indefinida) e Minosuke (21 anos).

Nessa época, o porto de Ishinomaki, localizado em Sendai, era um dos portos mais importantes do Japão. Dali embarcava grande quantidade de sacas de arroz para abastecer a cidade de Edo. A viagem acontecia geralmente em novembro, apesar da época de tempestades, pois essa era a época de colheita de arroz naquela região. OWakamiya-maru com seus dezesseis tripulantes também partiu com destino a Edo no dia 27 de novembro de 1793 , ano 5 da era Kansei com a certeza de que obtería bom hucro com a venda do carregamento. Porém, perdeu seu curso durante a tempestade e depois de navegar à detiva por mais de seis meses, chegou numa das Ilhas Aleutas já próximas ao Alasca. Salvo pelos nativos colonizados pelos russos, ali viveram por uns dois anos. Em 1795, os náufragos foram trazidos para Okhotsk por um comercianre de peles. Por ordem da Czatina Catarina II, os náufragos, divididos em três grupos, de agosro de 1795 a 1796, chegaram a Irktsk. Em função da morte da czarina, os japoneses permanecerem naquele local por longos oito anos, esquecidos pela coroa, tempo suficiente para a adaptação de alguns deles ao costume russo, como o tipo de alimentação e o modo de vida.

A adaptação dos náufragos ao novo ambiente, porém, não foi fácil. Dentre esses dezesseis tripulantes, dois morreram durante a viagem, dez permaneceram na Rússia convertendo-se em católicos otomanos e quatro optaram por retornar ao Japão.

Entre os que decidiram ficar no país que os acolheu, Zenroku, que sabia ler e escrever, resolveu trabalhar como intérprete e professor de língua japonesa, assumindo o papel importante na posterior negociação diplomática entre Japão e a Rússia. Por outro lado, os dados coletados através dos depoimentos dos náufragos sobre a língua e a cultura russa, assim como a cultura ocidental e a cultura dos nativos que habitavam o extremo oriente da Rússia, serve atualmenre como grande fonte para pesquisas antropológicas e lingüisticas.

A chegada dos japoneses no porto de Nagasaki a bordo do navio Nadiezheda ocorreu somente em 1804, após decorridos 11 anos desde o naufrágio, devido a inúmeros fatores históricos que ocorreram na Rússia.

A época em que houve o naufrágio, mais precisamente em 1793, a Rússia era governada pela Czarina Catarina II (1729 - 1796), que pretendia expandir seu império, tanto para o ocidente quanto para o oriente. O Japão também não era exceção visto que pela sua posiçãogeográfica, situava-se no local ideal para a saída ao Oceano Pacífico, com possibilidade de instalação de porros que não congelariam mesmo durante o inverno. Entretanto, após a repentina morte da czarina em novembro de 1796, o Czar. Pavel I (Paulo I) assumiu o poder. Ao contrário da sua antecessora, o novo Czat não tomou atitude positiva para amadurecer uma negociação com o Japão, adiando, assim, a viagem de retorno dos japoneses à terra natal por mais de seis anos. O seu estilo de governo introspectivo, entretanto, não agradou aos russos. Em 1801, após uma vida curta de cinco anos no poder, Czar Pavel I foi assassinado por seus conselheiros - ministros e em seu lugar o neto da Czarina Catarina II, o Czar. Alexandre I assumiu o poder. 
Seguindo a vontade da sua avó, o novo czar retomou a iniciativa para uma negociação com o Japão e a existência dos tripulantes naufragados foi relembrada.

Os japoneses, que nesta época viviam de trabalho como qualquer cidadão comum, foram chamados pelo $\mathrm{Czar}^{24}$. Indagados pessoalmente se desejavam retornar ao pais natal, os quatro responderam positivamente. Eram eles Tsudayu, Gihei, Sabei e Tajurou ${ }^{25}$. Zenroku, que já trabalhava no escritório de Nicolaj Petrovich Rezanov² ${ }^{26}$, futuro chefe da missão que levaria uma mensagem de intenção de amizade ao governo de Bakuf $u^{27}$, acompanhou os seus contetrâneos durante a viagem de retorno ao país de sol nascente.

Assim, no dia 16 de junho de 1803 - dia 18 de julho do calendário russo - a missão russa acompanhada de quatro japoneses partiu do porto de São Petersburgo rumo ao Japão. Eles navegaram a rota pelo Attântico, passando inicialmente pela Inglaterta e as ilhas Canárias. Abastecidos em Santa Catarina, Brasil, seguiram a rota em direção ao Occano Pacífico, atravessando o perigoso estreito de Magalhães.

O documento que relata a aventura desses japoneses divide-se em introdução e mais quinze volumes. O primeiro volume contém as informações sobre os primeiros acontecimentos do naufrágio até serem salvos por nativos das Ilhas Aleutas, sendo que há uma descrição minuciosa de usos e costumes do local além da descrição da fauna encontrada na ilha.

Os dez volumes seguintes descrevem o acolhimento dos náufragos pelos russos, colonizadores das Ihas Aleutas, suas viagens para São Petersburgo, então capital da Rússia, passando pela Okhotk e Irkutsk ${ }^{28}$. Em São Petersburgo, os japoneses conbeceram os primeiros balōes, o sistema de cultivo de plantas usando estufas além de casas de espetáculos de ópera e outros. Os depoimentos revelam a desenvolvida tecnologia do mundo ocidental.

Os volumes doze e treze tratam sobre a viagem de volta dos náufragos para o Japão no bordo do navio russo Nadiezheda, do qual cita sua passagem pelo Brasil. O documento registra inclusive o depoimento dos marinheiros que viveram a calmaria, temida pelos homens que viviam no mar naquela época.

"Segundo o Capitão, o mar entre as Ihbas Canárias e a América do Sulé o local mais calmo do mundo e corresponde à altura da linha do Equador. Segundo ele, tanto o vento como as ondas são calmas nesse local e que viajando por mais um dia, o vento passaria a soprar mais forte. Salientou que nossa presença em tal local era fantástica. Por causa das calmarias, o navio teve dificuldade em avançar. O mastro foi severamente danificado. Além disso, segundo Ivan Hyotarowitch ${ }^{29}$, a água sob a linha do Equador permanece imóvel,

24 Anos após o naufrágio, os japoneses vivian como artesãos, caçadores e comerciantes como qualquer um do povo russo. E interessante que oos depoimnentos não tem tegistro de maus tratos.

${ }_{25}$ Fonte: http://homepage2.nifty.com/snowwolf/kankaio.htm

26 Fonte: SUGIMURA, 'Tsutomu et alii, org. Kankai Ibun (Informaçōes exóticas ouvidas na viagem ao redor do mundo), organizado por OTSUKI Gentaku (1757-1827) e SHIMURA Hiroyuki (1769-1845). 1840 - Eextos originais e estudor. Tóquio: Yasaka Shobo, 1986, p. 465.

27 Bakufu - sistema de governo por militares consolidado no Japào no período de Tkugawa que perdurou até 1868 , quando o poder é retomado pelo Imperador Meiji.

${ }^{28}$ Fonte: SUGIMURA, Tsutomu et alii, org. Kankai Ibun (Informaçóes exótcas ouvidas na viagem ao redor do mundo), organizado por OTSUKI Gentaku (1757-1827) e SHIMURA Hiroyuki (1769-1845). 1840 - textos originais e estudos. T'óquio: Yasaka Shobo, 1986.

2: Tratàne do capitão do navio Nadiezheda, Ivan Fydorovich Krusenshtern (1770 - 1846) que acompanhou os japoneses at viagem. N.T. 
dificultando a medição da distância. Disse-nos que ao atingir essa latitude, há um ponto en que o navio não se move de forma alguma mas que, quando se desloca em direção da costa continental, surge uma corrente marítima tanto para o norte como para o sul, possibilitando a medição da distância. Por exemplo, pareceu-nos que houve um sinal em algum lugar indicando que surgiria um ven to que sopratia do norte se navegássemos por mais sete dias. (É dificil de acreditar nessa história) ${ }^{30 \prime \prime}$ (Otsuki, Shimura, 1807).

Para os japoneses daquela época, essa informação valiosa parecia simplesmente uma fantasia das mentes perturbadas dos náufragos. Hoje em dia sabe-se que na linha do Equador há realmente uma zona de encontro da corrente eólica do hemisfério sul com a do hemisfétio norte onde não há presença de corrente de ar, o que os antigos navegadores denominaram região de calmaria. Para os navios que andavam à vela, essa região era mais temida do que a zona de tempestades. De fato, na maioria dos diários de bordo dessa época há menção sobre essa região.

Saindo da calmaria, o navio finalmente aportou na tha de Santa Catarina. Alguns dos tripulantes desceram do navio e pisaram no solo brasileiro. Foi o início do contato de japoneses com o Brasil. Se foi grande a emoção quando o primeiro homem pisou pela primeira vez na superfície da lua, em junho de 1969 , para dar início a exploração do espaço, para o Japão esse fato pôde ter tido significado análogo $0^{31}$.

O fato que a esquadra norte-ameticana do comodoro Perry, composta por quatro navios, comandado por Matthew C. Perry (1794 - 1858) ter avançado na baía de Edo (atual Tóquio) em 8 de julho de 1853, trazendo uma mensagem do presidente norte-americana exigindo a abertuta do Japão e a assinatura do tratado de amizade entre os dois paises é demasiadamente conhecido não somente pelos historiadores mas por todas as pessoas que de alguma forma estudaram a história japonesa. Apelando à força, os Estados Unidos foram o primeiro país a firmar um tratado de amizade com o Japão, no dia 3 de agosto de 1854 , dando início ao processo de abertura total dos portos. A partir de então o Japão passou a firmar tratados internacionais com vários países do ocidente como Holanda, Rússia, Inglaterra e França.

As primeiras tratativas à negociação de acotdo de amizade entre Btasil c Japão iniciaramse em 1892, já independente do Portugal. A assinatura do Tratado de Amizade, Comércio e Navegação entre Brasil e o Japão ocorteu em Paris, no dia 5 de novembro de 1895 , recebendo a aprovação no Legislativo em 27 de novembro de 1897 pela Lei $n^{0} 419^{32}$. Assim, o Brasil, internalizando o Tratado Internacional, finalmente travou os laços diplomáticos com o Japão decorrido quase um século depois de os primeiros japoneses terem pisados no solo brasileiro. Portanto, os japoneses chegaram a conhecer o Brasil colonial, mesmo antes da sua independência do Reino de Portugal.

34 O texto em negrito representa os comentátios dos organizadotes do livro "Kankei bun".

${ }^{31}$ Nessa época, japào mantinha o comércio apenas com a Holanda cuja teligiăo não era católica. Mesmo assim, o sev contato com a terra era proibido de modo que eles somente aportavam na ilha artificial construida especialmente para esse firt chamada de dejitha, em Nagasaki. Fonte: SUGMMURA, Tsutomu et alis, org. Kankä Ibun (In formações exóticas ouvidas na viagem ao redor do tmundo), organizado por OTSUKLI Gentaku (1757-1827) e SHIMURA Hiroyuki (1769-1845). 1840 - textor originatis e estudos. Tóquio: Yasaka Shobo, 1986.

${ }^{32}$ Fonte: CAMPOS, Raul Adaberto de. Relafoes diplomaticas do Brasil de 1808 a 1912 Rio de Janeiro, Tyip. fornal do commercio, 1913, pp. 76. Ver tambén REIS, Maria Edileuza Fontenele, Brasileiros no Japcis: o elo bumano das relajöer bilaterais. NINOMYY, Masato, org a trad. 2.ed. São Paulo: Kaleidus-Prinus, 2002, p. 44. 
O volume quatorze descreve a chegada dos náufragos no porto de Nagasaki, em fevereiro de 1804, a inspeção dos objetos do navio e a entrega da carta imperial da Rússia desejando o intercâmbio com o Japão. Lá, os náufragos permaneceram por quase um ano até o retorno a Sendai, onde aguardavam seus familiares. Quanto ao emissário russo, Rezanov retornou ao seu país sem obter sucesso na negociação para atas uma relação díplomática com o Japão. A negação do Bakufu em firmar um tratado de amizade certamente desapontou o império russo, pois eles acreditavam que a licença concedida pelo governo japonês ao Laksman, em 1792, para usar seus portos valeria também para demais embarcações futuras ${ }^{33}$.

O último volume fornece uma visão global sobre a extensão geográfica dos cinco continentes, incluindo uma descrição da situação política da Holanda, uma perspectiva geopolítica de vários países, informações sobre a formação do tertitório do império russo, uma menção de Índia, Pérsia, arual lrã, etc., conforme enumerado nas páginas anteriores. Otsuki comentou nesse volume que somente o Japão mantêm-se isolado enquanto que a Rússia mantinha relações diplomáticas com todos outros países do resto do mundo.

Os primeiros contatos dos japoneses com o Brasil, como foi mencionado anteriormente, estão documentados no volume doze da coletânea. Nesse volume está descrita a viagem desde sua partida do porto de São Petersburgo, passando pela passagem pela linha do Equador, pela parada em llhas Canárias e Santa Catarina, até a chegada na Terra do Fogo onde os viajantes japoneses conheceram as maravilhas do extremo sul da Terra. É justamente esse volume que interessa à pesquisa do presente trabalho, pois documenta a chegada dos primeiros japoneses que pisaram no solo brasileiro. Através do estudo de inúmeras anoraçōes e descrições narradas pelos viajantes e mapas fornecidos pelo emissário russo, o Japão que vivia na auto-clausura pôde obter valiosas informações acerca do Brasil, até então somente conhecido por meio de informações obtidas por alguns livros vindos da Holanda.

\section{O navio russo traz os primeiros imigrantes japoneses ao Brasil}

A chegada dos primeiros imigrantes ao Brasil, a bordo do Kasato-maru, é cansadamente descrira e comentada. De fato, Kasato-maru, de bandeira japonesa aportou no porto de Santos no dia 18 de junho de 1908, ano 41 da era Meiji, trazendo primeiros 781 japoneses contratados para trabalharem nas fazendas de café e mais 12 imigrantes sem vínculo empregatício, como já foi citado anteriormente.

O fato, porém, pode ser analisado em uma dimensão maior, do ponto de vista das relações internacionais, não somente entre Japão e o Brasil, mas com uma visão mais global. Se o incidente internacional entre Rússia e Japão trouxe os japoneses ao Brasil, aquele país assumiu mais uma vez um papel importante para a consolidação do elo entre estes países.

Em 1904, o Japão ingressou na guerra contra a Rússia do Czar Alexandre I, dando inicio a guerra Russo-japonesa (1904-1905), que terminou com a vitória do Japão. Segundo o livro "Kasato-maru", organizado pela Comissão para a Comemoração do Cinqüentenário da Imigração Japonesa e editado em 1958, o navio Kasato-maru era um navio-hospital russo de nome Aliyoru que fazia parte da frota da força naval russa do mar Báltico. O fato é confirmado pelo depoimento do contramalmirante Ichiro Fukuda, comandante da divisão que tripulava o cruzador japonês camuflado Sado-maru que capturou os navios da frota marinha russa, Aliyoru e Kastroma, em 27 de maio de ano 38 da era Meiji (1905).

33 Sobre o assunto, Sugirnura comenta que essa interpretação equivocada por parte do governo russo ocomel devido no desconhecimento das línguas, tanto pelo lado japonês como russo. SUGIMURA, op. cit., p. 484 e ss. 